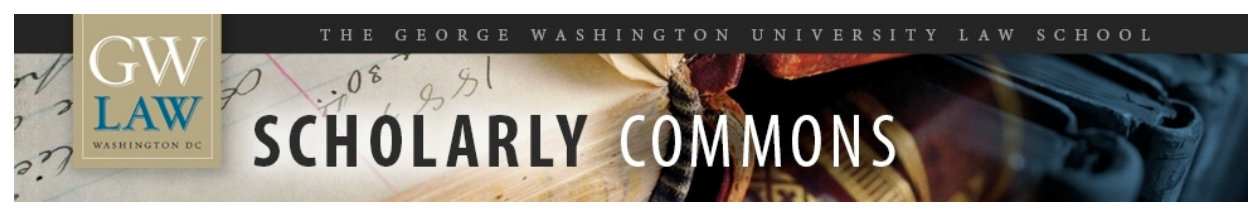

\title{
Extent of Cooperative Enforcement: Effect of the Regulator- Regulated Facility Relationship on Audit Frequency
}

Dietrich Earnhart

Robert L. Glicksman

George Washington University Law School, rglicksman@law.gwu.edu

Follow this and additional works at: https://scholarship.law.gwu.edu/faculty_publications

Part of the Law Commons

\section{Recommended Citation}

Earnhart, Dietrich and Glicksman, Robert L., Extent of Cooperative Enforcement: Effect of the RegulatorRegulated Facility Relationship on Audit Frequency (October 20, 2015). 5 Strategic Behavior \& the Environment 111-156 (2015); GWU Law School Public Law Research Paper No. 2015-44; GWU Legal Studies Research Paper No. 2015-44. Available at SSRN: http://ssrn.com/abstract=2676856

This Article is brought to you for free and open access by the Faculty Scholarship at Scholarly Commons. It has been accepted for inclusion in GW Law Faculty Publications \& Other Works by an authorized administrator of Scholarly Commons. For more information, please contact spagel@law.gwu.edu. 


\title{
Extent of Cooperative Enforcement: Effect of the Regulator-Regulated Facility Relationship on Audit Frequency
}

\author{
Dietrich Earnhart ${ }^{1}$ and Robert L. Glicksman ${ }^{2 *}$ \\ ${ }^{1}$ Department of Economics, University of Kansas, Lawrence, KS 66045, \\ USA; earnhart@ku.edu \\ ${ }^{2}$ The George Washington University Law School, 2000 H Street, NW \\ Washington, DC 20052, USA
}

\begin{abstract}
A spirited debate explores the comparative merits of two different approaches to the enforcement of environmental law: the noncooperative approach, which emphasizes the deterrence of noncompliance through inflexibly imposed sanctions, and the cooperative approach, which emphasizes the inducement of compliance through flexibility and assistance. Both scholarly and policymaking communities are interested in this topic of enforcement approach within the realms of finance, tax compliance, occupational safety, food and drug safety, consumer product safety, and environmental protection, among others. To inform this debate, our study explores enforcement of environmental protection laws where the debate has been especially spirited yet lacking in much empirical evidence. Specifically, our study empirically analyzes the effect of enforcement approach on the frequency of self-audits linked to compliance with wastewater discharge limits imposed on chemical manufacturing facilities. For this
\end{abstract}

${ }^{*}$ The research described in this article was conducted as part of a larger project financed by the U.S. Environmental Protection Agency (EPA) pursuant to STAR Research Assistance Agreement No. R-82882801-0. This article has not been formally

ISSN 1944-012X; DOI 10.1561/102.00000058

(C) 2015 D. Earnhart and R. L. Glicksman 
analysis, we view the enforcement approach as representing a relationship between a regulator and a regulated facility that is measured in multiple dimensions. The empirical results reveal that, in general, a cooperative relationship induces more frequent auditing and, in particular, a more stable and higher quality relationship increases audit frequency, while a completely fair relationship yields less frequent auditing. However, these conclusions may depend on the extent of regulatory monitoring and enforcement. Specifically, they rely on sufficiently lower monitoring and enforcement. Once the extent of monitoring and enforcement becomes sufficiently strong, the empirical results appear to support the opposite conclusions.

Keywords: Environmental management; compliance; enforcement approach; self-audits.

JEL Codes: K32, K42, Q53

\section{Introduction}

For years a spirited debate has explored the comparative merits of two different approaches to the enforcement of regulatory law: the noncooperative approach, which emphasizes the deterrence of non-compliance through inflexibly imposed sanctions, and the cooperative approach, which emphasizes the inducement of compliance through flexibility, including the provision of compliance assistance that is designed to induce facilities to address non-compliance pro-actively. (Most other studies refer to the "noncooperative" approach as the "coercive" approach or "deterrence-based" approach; in general, we use the term "noncooperative".) Both scholarly and policymaking communities are interested in

reviewed by EPA. The views expressed in this article are solely those of Robert Glicksman and Dietrich Earnhart. EPA does not endorse any products or commercial services mentioned in this manuscript. The authors thank Donald Haider-Markel and Tatsui Ebihara for their participation in the EPA STAR grant research project. The authors also thank Chris Drahozal, Joel Mintz, and Cliff Rechtschaffen for their very helpful insight. Dietrich Earnhart thanks Dylan Rassier, J. Mark Leonard, and Trisha Shrum for their valuable research assistance. 
this topic of enforcement approach within the regulatory realms that include finance, tax compliance, occupational safety, food and drug safety, consumer product safety, and environmental protection (Ayers and Braithwaite, 1992).

In the realm of environmental protection, a debate over enforcement is greatly warranted since compliance assurance represents one of the most contentious issues in the post-2000 EPA policy agenda (EPA, 2000; Glicksman and Earnhart, 2007). As in other regulatory realms, the debate focuses on the two identified approaches.

Supporters of the noncooperative model regard the deterrence of violations as the fundamental purpose of environmental enforcement (Markel, 2000, 2005; Mintz, 1995). These supporters also regard the imposition of enforcement sanctions, which make it more costly for regulated entities to avoid complying with their regulatory responsibilities, as the most effective way to induce regulated entities to comply with their regulatory obligations. Supporters of the cooperative approach to environmental enforcement focus more on compliance than deterrence, based on the premise that regulated facilities react to a variety of motives that supply sufficient incentives to comply with regulatory obligations even without inflexible imposition of sanctions (Andreen, 2007; Stoughton et al., 2001). In this light, a noncooperative approach may even be counterproductive if it engenders intransigence and ill will on the part of regulated facilities.

Since the initial implementation of environmental protection laws in the United States, environmental enforcement has shifted away from traditional, deterrence-based enforcement and towards a more partnershipbased, less adversarial approach that uses multiple tools for inducing compliance (Stoughton et al., 2001). In particular, during the 1990s, EPA improved cooperation between the agency and regulated facilities by adopting enforcement policies that were designed to provide a more flexible approach to inducing compliance with regulatory obligations by offering "compliance incentives" and "compliance assistance" to regulated facilities (Andreen, 2007). This shift most likely was prompted by a "broad agreement at the federal and state levels that the traditional, exclusive reliance on penalty-based enforcement approaches to compliance assurance is inadequate" (Stoughton et al., 2001). Accordingly to (Stahl, 1995), the EPA concluded that a penalty-based approach is reactive rather than proactive and is incomplete because it fails to 
reward voluntary compliance. Similarly, many states to some extent have replaced traditional enforcement with some form of cooperation (Andreen, 2007). However, no shift from a noncooperative approach to a cooperative approach has been complete. Despite the dichotomy between noncooperative and cooperative enforcement approaches, federal and state agencies rarely rely exclusively on one approach; studies of agency enforcement reveal that "most enforcers use a flexible, hybrid strategy that includes elements of both coercion and cooperation" (Rechtschaffen, 2004). Certainly, given the broad discretion that environmental statutes typically vest in federal and state agencies, these agencies possess a considerable range of choices when deciding the mix of noncooperative and cooperative techniques to apply in particular cases.

For all the debate that the recent emphasis on cooperative enforcement approaches has engendered, relatively little empirical research has been directed at a comparison of the two enforcement approaches. Specifically, few studies empirically test these competing theories about how best to induce environmental compliance or, more fundamentally, how best to spur regulated facilities to undertake better environmental management that in turn should lead to environmental compliance.

This study attempts to address the paucity of empirical evidence by examining the effect of the overall enforcement approach on the frequency of auditing conducted by chemical manufacturing facilities regulated under the Clean Water Act. For this empirical examination, we conducted a survey of all chemical manufacturing facilities regulated between 1999 and 2001. The survey responses indicate that, although most regulated facilities describe their relationships with wastewater regulators as generally either cooperative or noncooperative, these facilities also report that some particular aspects of their relationships are more consistent with cooperation, while other aspects are less consistent with cooperation. This assessment reveals that the relationship between a regulator and a regulated facility consists of multiple dimensions, which we claim are reflective of the overall enforcement approach. To be clear, our survey identifies only one aspect that clearly contrasts a cooperative approach and a noncooperative approach; for the remaining aspects, our survey simply identifies the extent of cooperation: more versus less.

Our empirical analysis exploits these multiple dimensions so our empirical results provide a more accurate portrayal of the effects of the 
overall enforcement approach on auditing frequency. By recognizing the nuanced nature of the relationships between regulator and regulated facilities, we are able to provide a more meaningful contribution to the ongoing debate over the effect of enforcement approach on the environmental behavior and performance of regulated facilities.

Empirical results indicate that a generally cooperative approach appears to induce more frequent auditing, while a completely fair treatment of regulated facilities appears to lower audit frequency. Similar to the general approach, both the stability and quality of the regulatorregulated facility relationship appears to increase auditing frequency. In general, our conclusions are moderately robust to the type of facility: major versus minor. However, these conclusions appear to depend on the extent of regulatory monitoring and enforcement since the underlying marginal effects depend on these regulatory conditions. Specifically, the conclusions and their underlying marginal effects rely on sufficiently lower monitoring and enforcement. Once the extent of monitoring and enforcement becomes sufficiently strong, the generated marginal effects appear to support the opposite conclusions.

The rest of this paper is organized as follows. The second section summarizes the previous theoretical and empirical literature. The third section presents the selection of the research sample, while briefly describing wastewater regulatory efforts. The fourth section constructs the econometric model. The fifth section describes the data. The sixth section presents the estimation results. The seventh section discusses the policy and research implications.

\section{Literature Review}

This section reviews the previous literature on the theoretical frameworks underlying the noncooperative and cooperative enforcement approaches and the few empirical studies that directly compare the two approaches in the environmental realm.

\section{Noncooperative and Cooperative Approaches to Enforcement: Theory}

A review of the legal, political science, and economics literature on environmental enforcement reveals a debate about the comparative 
efficacy of two different models of environmental enforcement: the noncooperative model and the cooperative model.

\section{Noncooperative Approach to Environmental Enforcement and Compliance: Theory}

The noncooperative model is premised on the idea that regulated facilities are rational economic actors whose principal motivations revolve around the maximization of expected benefits net of costs (Malloy, 2003; Spence, 2001). The noncooperative model postulates that decisions regarding compliance are based on self-interest; businesses comply when the costs of noncompliance outweigh the benefits of noncompliance (Vandenbergh, 2003). The benefits are avoided by compliance costs. The costs of noncompliance include any additional costs of achieving compliance once a violation is detected as compared to achieving compliance earlier, plus any applicable penalties. These costs can also include damage to the business's reputation, potential tort liability, and legal system expenses (Karpoff et al., 2005; Rechtschaffen and Markell, 2003; Vandenbergh, 2003).

The noncooperative model also proceeds on the premise that increasing the certainty and severity of penalties deters noncompliance (Becker, 1968). A facility's compliance status depends on the likelihood that violations will be detected and on the severity of imposed sanctions (Kagan et al., 2005). Thus, the essential task for enforcement agencies is to make penalties high enough and the probability of detection/enforcement great enough that it becomes economically irrational for regulated facilities to violate the law (Cohen, 2000).

In sum, the noncooperative model emphasizes the importance of policing and deterring violations as the essential core of environmental agencies' activities. Consistent with this emphasis, the EPA traditionally sought to impose sanctions that exceed the economic benefit the violators gained from noncompliance (Markel, 2005).

\section{Cooperative Approach to Environmental Enforcement} and Compliance: Theory

The cooperative model is premised on the assumption that corporations represent institutions that are influenced by a mix of civic and societal 
motives, not just maximization of profits. This model postulates that corporations are generally inclined to comply with the law (Rechtschaffen and Markell, 2003). Correspondingly, the cooperative model emphasizes compliance rather than the deterrence of noncompliance.

This emphasis alters the use of both inspections and enforcement. Within the cooperative model, an inspection is designed to facilitate compliance by providing advice to regulated facilities (Rechtschaffen and Markell, 2003). In contrast, within the noncooperative model, an inspection is primarily conducted in an effort to detect violations and collect evidence for subsequent enforcement actions. Under both models, facility inspections serve as threats of future enforcement action.

The cooperative model's emphasis on compliance also alters the use of enforcement actions. Under this model, regulated facilities may be afforded more opportunities to avoid sanctions by resolving noncompliance before a penalty is assessed or other enforcement action pursued than under the noncooperative model. As a result, the cooperative approach "emphasizes flexible or selective enforcement that takes into consideration the particular circumstances of an observed violation" (Scholz, 1984). Indeed, imposing penalties is viewed as a sign of the cooperative system's failure to obtain compliance (Rechtschaffen, 1998).

As an important extension of this logic, if businesses are generally committed to compliance even without a coercive enforcement presence, sanctions may not only be unnecessary but also be counter-productive. A sanction-oriented response to noncompliance may make regulated facilities resentful and less likely to cooperate with regulators in the future (Burby and Paterson, 1993; Kagan et al., 2005). In many contexts, random variations in facility operations or unexpected events may occasionally push a facility into noncompliance. A coercive response to these noncompliance events may breed especially strong resentment or ill will.

In essence, the cooperative model relies on flexible guidelines rather than uniform rules, an emphasis on ex ante prevention of violations rather than ex post sanctions for noncompliance, and compliance assistance from regulators (Burby, 1995). This model rests on the premise that regulated facilities should respond more positively to regulators' suggestions on how to achieve compliance than to the threat of coercive sanctions (Rechtschaffen and Markell, 2003). 


\section{Noncooperative versus Cooperative Enforcement: Empirical Studies}

Relatively few empirical studies analyze the use of cooperative enforcement strategies. Harrison (1995) states that past studies hailing the merits of cooperative enforcement lack empirical support. There is even less research directly comparing noncooperative and cooperative strategies. According to Rechtschaffen (1998), "[t]he argument that cooperation works better than deterrence to achieve compliance with environmental law ... is largely untested." Most evidence is anecdotal.

Some studies do analyze the efficacy of overall enforcement strategies First, Harrison (1995) analyzes the regulation of water pollution in Canada. She finds that rates of compliance with water pollution controls are significantly lower in the pulp and paper industry in Canada, where the cooperative approach to enforcement is generally followed, than in the United States. She concludes that the cooperative Canadian approach has delivered disappointing results compared to the U.S.'s relatively more adversarial approach. Second, Burby (1995) examines states' programs to reduce erosion and sedimentation pollution in urban areas. He concludes that "[t]he best performing state programs [for nonpoint sources of water pollution] tend to be those that use a highly coercive approach." Third, Burby and Paterson (1993) examine whether the cooperative approach is better suited to inducing compliance with performance standards than with specification (or design) standards. Their results show that "a cooperative approach to enforcement has much more impact on the degree of compliance attained for performance standards than for specification standards." Fourth, Andreen (2007) examines compliance rates for major dischargers under the CWA. He finds that compliance rates remained static during the period in which many states were replacing traditional enforcement with some type of cooperative enforcement. He concludes that "[t]he new, more flexible approach has not improved rates of compliance."

While these empirical studies help to inform our understanding of enforcement strategies and their relative efficacy, only one study (Burby, 1995) gathers facility-specific data on the type of relationship between regulators and regulated facilities and no study considers this relationship as consisting of multiple dimensions. In contrast, the present study examines both of these aspects. In particular, the present 
study distinguishes between the relative presence of one enforcement approach versus the other approach by assessing multiple dimensions. ${ }^{1}$

\section{Empirical Application}

\section{Selection of Research Sample}

To examine the effect of enforcement strategies, this study examines a specific element relating to compliance with environmental protection regulations: the frequency of wastewater-related self-audits implemented by U.S. chemical manufacturing facilities whose wastewater discharges were regulated by effluent limits imposed within the Clean Water Act's National Pollutant Discharge Elimination System (NPDES) permit program between 1999 and 2001. By focusing on regulated facilities, our analysis is able to focus on environmental audits that include an assessment of compliance with the noted NPDES effluent limits. Unlike several previous studies of environmental behavior, our study considers facilities of all sizes, especially both "minor" and "major" facilities as classified by the NPDES system.

We choose the industrial sector of chemical and allied products as the focus of our study because it serves as an excellent vehicle for examining the efficacy of enforcement strategies on regulated facilities' auditing practices First, The EPA has demonstrated a strong interest in this sector as evidenced by its study (joint with the Chemical Manufacturing Association [CMA], which later became the American Chemistry Council $[\mathrm{ACC}]$ ) on the root causes of noncompliance in this sector (EPA, 1999) and its study of the compliance history for this sector [Chemical Industry National Environmental Baseline Report 1990-1994 (EPA 305-R-96002)]. Consistent with this interest, two of the chemical industrial sub-sectors, industrial organics and chemical preparations (SIC-codes 2869 and 2899), were regarded by the EPA as priority industrial sectors during a portion of the study period. Second, This sector is expected to display a wide scope in the facilities' extent of auditing practices. Consistent with this expectation, a substantial portion of the sampled

\footnotetext{
${ }^{1}$ Notable studies explore specific cooperative approaches within a standard noncooperative arrangement (Helland, 1998; Short and Toffel, 2010; Stretesky and Gabriel, 2005; Toffel and Short, 2011).
} 
facilities never audit over the three-year sample period, while several facilities audit their operations at least monthly. Third, This sector permits the analysis to exploit similarities and differences across subsectors. Fourth, This sector is responsible for a significant portion of the nation's industrial output and a significant portion of all wastewater discharges by facilities subject to CWA regulation. ${ }^{2}$

Facilities may control their wastewater discharges in various ways. In general, facilities use end-of-pipe treatment technologies or proactive environmental management practices, which collectively may constitute an environmental management system (EMS). In general, an EMS represents a set of management rules and procedures designed to reduce a facility's environmental impacts and involves components, such as audit programs and environmental training (Barla, 2007).

Examination of proactive environmental management practices is certainly relevant to policy development and trends in business management. Both the EPA and state environmental protection agencies have created programs to encourage the adoption of environmental management systems. These programs offer technical assistance, recognition, and regulatory benefits to facilities that employ an environmental management system (Crow, 2000). Similarly,"business-led" initiatives have promoted participation in trade association programs emphasizing environmental management codes, such as the Responsible Care program of the American Chemistry Council, or the adoption of international certification standards for environmental management, such as the International Standards Organization (ISO) 14001 program.

Some empirical studies focus on the presence or absence of an EMS (e.g., Arimura et al., 2008; Barla, 2007). However, some of the EMS components may not represent activities that effectively lead to improved environmental performance (Barla, 2007). Rather than examining the mere presence of a broad set of management activities or analyzing a count of practices, this study focuses on the use of a particularly tangible management activity - environmental regulatory compliance

\footnotetext{
${ }^{2}$ The chemical industry is not necessarily representative of all industrial sectors. Indeed, its unique attributes contribute to our interest in studying it. For example, some firms in the chemical industry have demonstrated an interest in promoting pollution reduction and prevention through efforts prompted by the Responsible Care program, which is a voluntary initiative supported by the American Chemistry Council. Thus, our results need not generalize to other industries regulated under the Clean Water Act.
} 
auditing - that is strongly expected to improve performance. Previous empirical studies support this expectation (Khanna and Widyawati, 2011; Short and Toffel, 2010; Toffel and Short, 2011); in particular, (Earnhart, 2004a,b) reveal that more audits lead to better compliance with wastewater discharge limits. As important, beginning in the mid-1980s, the EPA has promoted self-audits as a tool for improving environmental performance, especially for increasing environmental compliance (Evans et al., 2011). As evidence of this promotion, the EPA has integrated environmental auditing into its compliance and enforcement strategy; specifically, the EPA began in 1997 to include increased environmental auditing in its strategic plan for improving compliance with environmental regulations (EPA, 1997; Evans et al., 2011).

A compliance audit represents a systematic, documented, and objective review of a facility's operations, which allows the facility to evaluate its compliance relative to audit criteria (American Society for Testing and Materials [ASTM], 2003). The EPA defines an environmental audit as "a systematic, documented, periodic and objective review by regulated facilities of facility operations and practices related to meeting environmental requirements." 3 Rather than examining the mere presence or absence of an audit program, this study focuses on the frequency of audits for three reasons First, Most guidelines recommend that environmental self-audits be conducted at least annually (Ebihara and Irminger, 2005). Thus, many facilities may conduct at least one audit per year. Second, Regularly scheduled self-audits contribute to both stronger overall environmental management and to more consistent compliance with relevant regulations (Wilson and Thomas, 1998). Thus, greater frequency should lead to better environmental management. Third, We wish to examine the extent of environmental management adoption in a new way.

Unlike other studies that examine the extent of adoption by summing across dichotomous decisions (e.g., Anton et al., 2004; Khanna and Anton, 2002) ${ }^{4}$ our study examines the extent of adoption by measuring the frequency with which facilities audit their operations.

\footnotetext{
3"Interim Guidelines on Environmental Auditing Policy Statement," 50 FR 46504 (November 8, 1985), Section II.A.

${ }^{4}$ Other studies examine multiple measures of environmental management but do not exploit the presence of multiple measures in order to calculate the extent of adoption, (e.g., Dasgupta et al., 2000; Arimura et al., 2008).
} 
In addition, an empirical focus on audits arguably dominates an empirical focus on the presence of EMS certification, e.g., ISO 14001. The presence of a certified EMS may reflect decisions made several years in the past since once certification is obtained it is generally maintained over time. In contrast, audit frequency reflects ongoing management decisions. ${ }^{5}$ Thus, we are better able to understand the timing of management decisions.

\section{Water Pollution Control and Enforcement}

The chosen sample and focus on audit frequency facilitates an effective analysis of chemical manufacturing facilities' responses to regulatory efforts to control wastewater-related pollution. These efforts begin with the issuance of facility-specific permits, which impose effluent limits that represent performance-based standards. To ensure compliance with the permitted effluent limits, the EPA and state agencies periodically inspect facilities and take enforcement actions as needed. In general, inspections represent the backbone of environmental agencies' efforts to monitor compliance and collect evidence for enforcement. As for enforcement, agencies use a mixture of informal enforcement actions (e.g., warning letters) and formal enforcement actions (e.g., administrative orders, fines). Our analysis considers all types of enforcement actions.

\section{Econometric Approach}

To assess the effect of the overall enforcement approach, this section structures the econometric analysis that estimates the functional relationship between audit frequency and multiple measures of the overall enforcement approach employed against the sampled facilities.

\section{Effect of Regulator-Regulated Facility Relationship}

In each relevant year of the sample, a facility must choose its environmental management level, represented by the count of self-audits,

\footnotetext{
${ }^{5}$ These advantages notwithstanding, we acknowledge that the quality of a given environmental audit may vary across facilities and across time for a particular facility. We argue that this possible variation in quality is dominated by the variation in quantity examined here.
} 
which depends on several factors, especially the overall enforcement approach.

Given the strongly empirical thrust of this study, we do not attempt to model formally the relationship between audit frequency and overall enforcement approach. Instead, we rely upon our review of theoretical studies (provided in Subsection 2.1.1) for generating the basic hypotheses - (1) more cooperation is better and (2) less cooperation is better and by extension the hypotheses associated with individual dimensions of the overall enforcement approach.

To test these hypotheses, we assess the effects of multiple dimensions that we claim are reflective of an overall enforcement approach on audit frequency. For each dimension, we identify a pair of hypotheses. The first dimension captures the general relationship between the regulator and the regulated facility: (1) generally cooperative or (2) generally coercive. Clearly the particular hypotheses are identical to the two basic hypotheses.

The second dimension captures the prevalence of fair treatment of the facility by the regulator: (1) always fair, (2) sometimes fair, or (3) always unfair. Environmental regulation is commonly perceived by regulated facilities as "unfair"; by extension, inflexible enforcement of this regulation might also be perceived as "unfair" (Zinn, 2002). More directly, an excessively stringent approach may be counterproductive by engendering perceptions that enforcement is "unfair" (Faure, 2012; Hawkins, 1984). In contrast, a cooperative enforcement approach, which is flexibly implemented, should mitigate the perceived unfairness of regulation and enforcement directly. Thus, regulated facilities could view cooperative enforcement as "fair." Under the co-operative model, greater fairness engenders good will, which induces more frequent auditing. Under the noncooperative model, greater fairness might dull the incentive to comply, leading to less frequent auditing.

The third dimension captures the stability of the relationship as reflected in the assignment of regulatory agency officials: the facility typically works (1) with the same water regulatory official or (2) with multiple regulatory officials that vary with circumstances. ${ }^{6}$ We posit

\footnotetext{
${ }^{6}$ The presence of multiple regulators does not reflect additional regulatory attention due to poor management or weak compliance; instead, this presence reflects the specialization of regulatory oversight in certain cases, e.g., certain regulatory personnel understand particular treatment technologies better.
} 
that regulated facilities typically find it easier to maintain a cooperative relationship with a single regulator than with multiple regulators whose approaches to compliance may differ and who may not understand the facility's operation in its entirety. By working with a single regulator, presumably a facility enjoys better contact and coordination with the regulatory agency, along with more instruction offered by the regulator. Given greater stability leading to more cooperation, under the cooperative model, greater stability prompts more frequent auditing. Under the noncooperative model, greater stability may not substantially affect audit frequency.

The fourth and fifth dimensions capture the quality of the working relationship as reflected in a facility's decision to seek assistance from the regulator's supervisor or an elected official to help with a difference of opinion between the facility and the regulator. The lack of a request reflects less friction and more goodwill between the regulator and facility, that is, more cooperation, than the existence of a request. Thus, under the cooperative model, the request for assistance indicates friction, which is expected to lower audit frequency, while under the noncooperative model, the request for assistance indicates less cooperation, which is expected to induce more frequent auditing.

The sixth dimension captures the physical proximity of the regulator involved in the relationship as reflected in the type of regulatory agency engaging the facility: (1) regional EPA agency or (2) state agency. We conjecture that regulated facilities may tend to work more cooperatively with state regulators than with federal regulators because state regulators tend to work physically closer to regulated facilities. Under the cooperative model, closer proximity spurs more frequent auditing. Under the noncooperative model, closer proximity does not influence auditing.

The last dimension captures the level of trust supported by the relationship as reflected in a facility's willingness to allow regulators access to plant operations if the regulators arrive unannounced. The more likely a facility is to allow unannounced access, the more cooperative we regard the relationship. Thus, under the cooperative model, greater trust induces more frequent auditing, while under the noncooperative model, greater trust induces less frequent auditing.

By incorporating all seven enforcement strategy dimensions into the estimated functional relationship, our analysis allows each dimension to 
influence audit frequency independently. This estimation permits the direction of influence and degree of importance to differ across dimensions. Based on the estimation results, we test each of the identified hypotheses.

\section{Effects of Other Factors on Audit Frequency}

To isolate the effect of the overall enforcement approach on audit frequency, the analysis controls for the influence of particular government intervention - inspections and enforcement actions - in two dimensions. The first dimension considers the ex ante general "threat" of receiving an intervention in the future based on the experiences of a large number of facilities, while the second dimension considers adjustments to this general threat based on the specific government interventions taken against particular facilities in the recent past (Cohen, 2000).

To calculate the ex ante general threat of a government intervention, each facility gauges its expectation of monitoring and enforcement based on the observed experience of other similar facilities, that is, each facility uses others' experiences to form its own beliefs (Sah, 1991). This need to form expectations about interventions stems from the uncertain nature of inspections and sanctions. When capturing the threat of enforcement actions, the analysis examines the count of actions taken against all other "similar" facilities: other regulated chemical facilities in the same EPA region and year, while distinguishing between major and minor facilities (i.e., a major facility bases its expectations on the experiences of other major facilities; similarly for minor facilities). The analysis then divides each aggregate count of enforcement actions by the number of other major or minor chemical facilities operating in each EPA region of the given year. To capture the threat (or likelihood) of an inspection, the analysis employs two proxies based on the annual aggregate count of inspections against other chemical facilities in the same location and year, as with enforcement actions. One proxy captures the state inspection likelihood, based on facilities in the same state, and the other proxy captures the federal inspection likelihood, based on facilities in the same EPA region. Then the analysis divides each aggregate inspection count by the number of other major or minor chemical facilities operating in each state or EPA region (as relevant) of the given year. 
Facilities may make adjustments to these general threats based on recent interventions taken at specific facilities (Magat and Viscusi, 1990). In essence, these experiences prompt facilities to update their expectations of the intervention threats. Facilities most likely need at least a few weeks, if not several months, to respond to interventions. Even though the study measures the exact date of an intervention, audits are recorded only on an annual basis. In order to lag properly the interventions when constructing the relevant regressors, the analysis considers interventions from the preceding calendar year. (Without this type of separation, some of the audits may actually precede some of the interventions in a given year.) The analysis generates separately the cumulative count of enforcement actions, state inspections, and federal inspections taken against a specific facility in the preceding calendar year.

The effects of government interventions targeted against particular facilities may more closely align with the effect of the regulator-regulated facility relationship. Thus, our study should focus more attention on specific adjustment and less attention on the general threat. Consequently, our study analyzes first only the effect of specific adjustment and then analyzes both the effects of specific adjustment and general threat.

The expected effects of government interventions on audit frequency depend on the theoretical model. Under the noncooperative model, both state and federal inspections should induce more frequent audits. However, under the cooperative model, state inspections should induce more frequent audits, while federal inspections may induce less frequent audits if the presence of federal inspectors is perceived as "heavy handed." 7 The expected effects of enforcement are similar to those of federal inspections under the two models.

Other regulatory factors may also affect audit frequency. The analysis attempts to control for variation in regulatory pressure not reflected in the aforementioned measures by including EPA regional indicators as regressors. Inclusion of these regional indicators is a

\footnotetext{
${ }^{7}$ We acknowledge that the distinction between state and federal inspections is weaker in our analysis since we control for the overall enforcement approach. Other studies examine more closely this distinction between state and federal inspections (Earnhart, 2004b, 2009).
} 
blunt tool for controlling "un-measured" variation in monitoring and enforcement across space. This inclusion forces the analysis to identify the effect of the overall enforcement approach based exclusively on intraregional variation, which may be insufficient for the task. Consequently, we reserve the inclusion of regional indicators as only a means for assessing the robustness of the empirical results.

Audit frequency also depends on facility- and firm-level characteristics First, Industrial sub-sector indicators help to control for variation in facilities' abilities to monitor their operations, including their production processes, based on the type of product being manufactured. The analysis includes two sub-sectoral indicators: organic chemical indicator and inorganic chemical indicator, with "other chemicals" as the omitted category. Second, Audit frequency may depend on the size of the regulated facility. The analysis measures facility size using two proxies. The number of employees represents the more common proxy of facility size. The NPDES facility classification represents the less common proxy but potentially the more relevant proxy for understanding the influence of facility size on audit frequency. The analysis includes a "major facility" indicator, with "minor facility" as the omitted category. By assessing the influence of these two facility size proxies, the analysis may be able to discern the presence of any economies or diseconomies of scale with respect to audit frequency. Third, Audit frequency may depend on the facility's age. Older facilities may be less likely to audit their operations or may audit their operations less frequently because facilities built years ago were not designed to facilitate easy monitoring. Alternatively, newer facilities may audit less frequently because their operations involve fewer problems that stem from wear and tear (e.g., leaks). Fourth, Audit frequency may depend on the facility's years of experience in the NPDES regulatory system. Over time, facilities may gain a better understanding of the regulatory system, thus, reducing the benefits of a proactive approach, i.e., experience substitutes for the insight gleaned from audits. Fifth, Firm ownership structure, as represented by the distinction between publicly held firms and privately held firms, reflects a host of dimensions. For example, publicly held firms stand to lose more from negative news regarding their environmental management, prompting facilities owned by publicly held firms to audit more frequently. The analysis includes a "publicly held" indicator, with "privately held" as the omitted category. 


\section{Data Collection}

\section{Data Sources}

In order to examine the effect of overall enforcement approach on the audit decisions of chemical manufacturing facilities, this study gathers information from various data sources. Most important, we implemented a survey of regulated chemical facilities, which gathered data on the nature of facilities' relationships and interactions with wastewater regulators, environmental management practices, especially wastewater selfaudits, and facility characteristics (e.g., age). We also gathered publicly available data. We gathered information on firm ownership structure from the EPA Toxic Release Inventory (TRI) database, Business and Company Resource Center database, and Compustat/Research Insight database. We also collected data from the EPA Permit Compliance System (PCS) database, which records information on NPDES facilities, on each facility's (1) location, (2) major or minor classification, and (3) four-digit standard industrial classification $[\mathrm{SIC}]$ code. ${ }^{8}$ From the PCS database, we also gathered data on state and federal inspections. And we gathered complementary data on enforcement actions from the PCS database and the EPA Docket database.

\section{Survey of Regulated Chemical Manufacturing Facilities: Implementation}

To implement our survey of chemical manufacturing facilities, we first identified the proper population of facilities to survey. The population is based on a full extract drawn from the EPA's PCS database as of September, 2001. In order to screen for currently regulated facilities, we applied the following criteria to facilities: (1) possessed an NPDES permit; (2) faced restrictions on their wastewater discharges, (3) were operating as of 2002, and (4) discharged pollutants into surface water bodies. ${ }^{9}$ Application of these criteria identified 1003 facilities to contact.

\footnotetext{
${ }^{8}$ The analysis aggregates the four-digit SIC codes into three broader sectoral categories: organic chemicals, inorganic chemicals, and "other" chemicals. The broad category of organic chemicals includes the following four-digit SIC codes: 2821, 2823, $2824,2843,2865,2869,2891$, and 2899 . The broad category of inorganic chemicals includes the following four-digit SIC codes: 2812, 2813, 2816, 2819, 2873, and 2874.

${ }^{9} \mathrm{We}$ focus on facilities discharging into surface water bodies because facilities discharging into publicly owned treatment works face a distinctively different regulatory regime.
} 
Of those facilities contacted between April 2002 and March 2003, 736 refused to participate in the survey, while 267 facilities completed at least $90 \%$ of the survey, implying a $27 \%$ response rate. This rate is comparable to previous large-scale surveys of industrial sectors (e.g., Arimura et al., 2011, 2008; Nakamura et al., 2001) and lies above the average response rate of $21 \%$ as identified by a review of 183 studies based on business surveys published in academic journals (Paxson, 1992). [An online appendix addresses the possible concern of sample selection bias.]

\section{Summary of Data}

This subsection summarizes the collected data, with a focus on the survey-derived data. Table 1a tabulates the distribution of self-audits

Table 1a: Statistical summary: Distribution of audit counts.

\begin{tabular}{crrcc}
\hline Audit count & $N$ & \multicolumn{1}{c}{ Pct } & Cumulative $N$ & Cumulative Pct \\
\hline 0 & 85 & 13.89 & 85 & 13.89 \\
1 & 241 & 39.38 & 326 & 53.27 \\
2 & 70 & 11.44 & 396 & 64.71 \\
3 & 18 & 2.94 & 414 & 67.65 \\
4 & 67 & 10.95 & 481 & 78.59 \\
5 & 12 & 1.96 & 493 & 80.56 \\
6 & 6 & 0.98 & 499 & 81.54 \\
8 & 3 & 0.49 & 502 & 82.03 \\
10 & 1 & 0.16 & 503 & 82.19 \\
12 & 64 & 10.46 & 567 & 92.65 \\
13 & 1 & 0.16 & 568 & 92.81 \\
17 & 2 & 0.33 & 570 & 93.14 \\
20 & 2 & 0.33 & 572 & 93.46 \\
24 & 7 & 1.14 & 579 & 94.61 \\
27 & 1 & 0.16 & 580 & 94.77 \\
36 & 3 & 0.49 & 583 & 95.26 \\
40 & 4 & 0.65 & 587 & 95.92 \\
45 & 4 & 0.65 & 591 & 96.57 \\
50 & 4 & 0.65 & 595 & 97.22 \\
52 & 17 & 2.78 & 612 & 100.00 \\
\hline
\end{tabular}

Note: Based on sample used for estimation of year-specific equations. 
performed over a given calendar year by a particular facility. The tabulation reveals that nearly $86 \%$ of the sample facilities perform at least one audit per year; thus, only $14 \%$ of the facilities lack an audit program. As expected, the distinction between no audits and some audits does not divide the sample strongly. The median facility performs a single audit per year. One to three audits per year are conducted by a majority of the facilities (54\%). Wastewater compliance is typically assessed monthly via submission of a monthly discharge monitoring report (DMR) to a regulatory authority; a good portion of facilities $(10 \%)$ perform audits at a frequency identical to this compliance reporting activity. ${ }^{10}$

Table 1c summarizes the dimensions reflecting a facility's relationship with its regulatory authority. Only $3 \%$ of facilities state that their relationship is "generally coercive," while $97 \%$ state that it is "generally cooperative." Moreover, $19 \%$ of facilities report that treatment by its regulator is "sometimes fair, sometimes unfair," while $81 \%$ report that it is "always fair," yet no facility reports that its treatment is "always unfair." Table 1c also indicates that $58 \%$ of facilities typically work with the same regulator, while $42 \%$ typically work with multiple regulators. Additionally, $79 \%$ of facilities did not seek help from the supervisor of the regulator, while $21 \%$ did so. Similarly, $95 \%$ of facilities did not request assistance from an elected official, while $5 \%$ did make a request. In addition, $99 \%$ of facilities report that they typically work with state regulators, while only $1 \%$ report that they typically work with federal regulators. ${ }^{11}$ Lastly, $90 \%$ of facilities are "always likely" to allow regulators access to plant operations if regulators arrive unannounced,

\footnotetext{
${ }^{10}$ Seven percent of the sample facilities perform more than 12 audits per year (i.e., more frequently than monthly audits). The presence of these relatively high audit frequencies may raise concerns. Fortunately, the presence of these higher audit frequencies does not drive the results. Estimation of a subsample that excludes all observations with a greater than monthly audit frequency generates results highly similar to those reported. Moreover, the distribution of these higher audit frequencies reveals a systematic pattern of audits. A strong majority of these observations lie at identifiable frequencies: semi-monthly audits $($ count $=24)$ and weekly audits (count $=52)$.

${ }^{11}$ The predominance of state regulators reflects the fact that EPA has delegated NPDES permitting authority to state environmental agencies in most states. As of 2006, only five states had not received authority to administer at least some aspect of the NPDES permit program.
} 
Table 1b: Statistical summary: Correlations between measures of regulator-regulated facility relationship.

\begin{tabular}{lcccccc}
\hline Measure of relationship & {$[1]$} & {$[2]$} & {$[3]$} & {$[4]$} & {$[5]$} & {$[6]$} \\
\hline [1] Allowing regulator & & & & & & \\
access to plant without & & & & & \\
announcement: always & & & & & \\
likely versus not & & & & & & \\
[2] Typical type of & 0.089 & & & & & \\
regulator: state versus & $(0.162)$ & & & & \\
federal & & & & & \\
[3] Stability of interaction: & 0.021 & 0.106 & & & \\
Same individual versus & $(0.745)$ & $(0.096)$ & & & \\
multiple individuals & & & & & \\
[4] Treatment of regulated & -0.055 & 0.070 & 0.224 & & \\
facility by regulator: & $(0.382)$ & $(0.267)$ & $(0.000)$ & & & \\
always fair treatment & & & & & & \\
versus not always fair & & & & & \\
[5] Overall relationship: & -0.054 & -0.015 & 0.099 & 0.345 & & \\
cooperative versus coercive & $(0.388)$ & $(0.811)$ & $(0.115)$ & $(0.000)$ & & \\
[6] Requested assistance & 0.015 & -0.054 & 0.059 & 0.222 & 0.222 & \\
from regulator's supervisor: & $(0.808)$ & $(0.394)$ & $(0.350)$ & $(0.000)$ & $(0.000)$ & \\
no versus yes & & & & & & \\
[7] Requested assistance & 0.055 & -0.024 & 0.033 & 0.080 & 0.076 & 0.221 \\
from elected official: no & $(0.383)$ & $(0.709)$ & $(0.602)$ & $(0.205)$ & $(0.227)$ & $(0.000)$ \\
versus yes & & & & & &
\end{tabular}

Note: Based on a single year's subsample; $p$-values shown in parentheses.

while $9 \%$ are either "likely" or "somewhat likely" to allow access, yet no facility is "not at all likely" to allow access. ${ }^{12}$

Next, the analysis compares the responses to the individual relationship-related questions by calculating Pearson pairwise correlation coefficients between all possible pairs of relationship elements; these correlations are reported in Table $1 \mathrm{~b}$. In general, these statistics reveal only

\footnotetext{
${ }^{12}$ As complementary analysis, we assess the distribution of each overall enforcement approach dimension for each state separately. As noted, the state regulator serves as the primary regulator for nearly all of the sampled facilities. Accordingly, we exclude the few facilities for whom an EPA regional office serves as their regulator. Our assessment reveals that, in nearly all of the states and for all of the enforcement approach dimensions, state regulators employ a similar overall enforcement approach against most but not all facilities. Thus, variation exists even at the state level in general. Details are available upon request.
} 
weak correlation between the various measures capturing the relationship between the regulator and the regulated facility. Of the 21 pairwise correlations, only 6 are positive and statistically significantly different from zero (i.e., $p \leq 0.10$ ). Of these significantly positive correlations, the largest magnitude is only 0.35 , indicating limited connection between these pairs of responses. As important, 5 of the correlations are actually negative though the coefficients are insignificantly different from zero. The remaining 10 correlations are positive but insignificantly different from zero. This analysis demonstrates that the relationship between a regulator and a regulated facility consists of multiple dimensions. In other words, no single underlying dimension seems to reflect all of the responses. ${ }^{13}$

Given the survey question structure and the response patterns, only one dimension demands manipulation to create a dichotomous indicator. If a facility is "always likely" to allow a regulator access to the facility's operations, the relationship is deemed "more cooperative." If a facility is only "likely" or "somewhat likely" to allow access, the relationship is deemed "less cooperative."

Similar to many studies of environmental management that rely on surveys, not all of our sampled facilities provide complete information on the dependent and independent variables. Of the 267 facilities who completed most of the survey, 215 provide complete information.

Table 1c summarizes the dependent variable and the remaining regressors.

\footnotetext{
${ }^{13}$ We also assess Pearson pairwise correlation coefficients between the seven overall enforcement approach elements and the three specific government intervention factors. For the correlations relating to state inspections, only 2 of 7 correlations prove statistically significant at the $10 \%$ level or better (both correlations are positive) and all of the correlation magnitudes range merely between -0.05 and 0.12 . For the correlations relating to federal inspections, none prove statistically significant and the magnitudes range merely between -0.02 and 0.06 . For the correlations relating to environmental actions, none prove statistically significant and the magnitudes range merely between -0.07 and 0.05 . Thus, none of these results indicates any concern about collinearity between overall enforcement approach and government interventions.
} 
Table 1c: Statistical summary: Means and standard deviations of regression variables.

\begin{tabular}{lcrr}
\hline Variable & Mean & Std. dev. \\
\hline Audit Count & Dependent variable & & \\
& & 5.580 & 10.959
\end{tabular}

Regulator-regulated facility relationship dimensions

Generally cooperative (vs generally coercive)

$0.967 \quad 0.178$

Always fair treatment (vs sometimes fair treatment)

$0.810 \quad 0.392$

Same individual regulator (vs multiple regulators)

$0.582 \quad 0.494$

No request for assistance from regulator's supervisor (vs request)

$0.791 \quad 0.407$

No request for assistance from elected official (vs request)

$0.946 \quad 0.226$

State is typical regulator (vs federal)

$0.994 \quad 0.040$

Always likely to allow unannounced access (vs likely/somewhat

$0.895 \quad 0.306$ likely)

\section{Other Regressors}

Organic chemical manufacturing (vs "other chemicals")

$0.443 \quad 0.497$

Inorganic chemical manufacturing (vs "other chemicals")

$0.301 \quad 0.459$

Major facility classification (vs minor facility)

$0.420 \quad 0.494$

Facility employees (count)

$268.558 \quad 491.257$

Age of facility (years)

Facility's experience with NPDES system (years)

$43.433 \quad 24.022$

Facility owned by publicly held firm (vs privately held firm)

$18.727 \quad 8.387$

Preceding calendar year state inspections (count)

$0.641 \quad 0.480$

Preceding calendar year federal inspections (count)

$0.784 \quad 1.499$

Preceding calendar year enforcement actions (count)

$0.042 \quad 0.246$

Annual state inspections of others/No. of other facilities

$0.178 \quad 1.344$ (count/facility)

Annual federal inspections of others/No. of other facilities

$0.808 \quad 1.056$ (count/facility)

Annual enforcement actions at others/No. of other facilities (count/facility)

EPA Region $1(1,0)^{\mathrm{a}}$

$0.035 \quad 0.056$

EPA Region $2(1,0)^{\mathrm{a}}$

0.182

EPA Region $3(1,0)^{\mathrm{a}}$

0.085

0.279

EPA Region $4(1,0)^{\mathrm{a}}$

$0.142 \quad 0.349$

EPA Region $5(1,0)^{\mathrm{a}}$

$0.263 \quad 0.441$

EPA Region $6(1,0)^{\mathrm{a}}$

$0.160 \quad 0.367$

EPA Region $7(1,0)^{\mathrm{a}}$

$0.204 \quad 0.403$

$0.070 \quad 0.256$

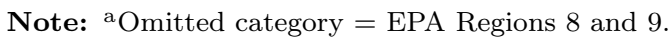




\section{Estimation Methods and Results}

\section{Estimation Methods}

This sub-section describes the estimation methods employed to examine the link from enforcement approach to audit frequency while addressing important econometric considerations.

As one important econometric consideration, our primary explanatory variables - measures of the enforcement approach — may be endogenous regressors. The validity of this concern over endogeneity varies across the measures of the enforcement approach. On one end of the spectrum, certain measures clearly represent decisions made by the regulator or facility, e.g., facilities' decisions to request assistance from a regulator's supervisor or elected official. On the other end of the spectrum, certain measures are most likely exogenously determined. For example, the primary type of regulator - state versus federal depends on whether a state agency has primacy over the NPDES program, which is not specific to a particular facility. To a lesser extent, interaction with the same individual regulatory official rather than multiple regulatory officials may simply reflect personnel decisions made independent of a particular facility.

We assess this endogeneity concern by implementing tests of exogeneity. Testing the exogeneity of seven regressors is beyond the means of standard statistical tools. For example, in their highly cited research, Stock and Yogo (2005) consider a maximum of three endogenous regressors when tabulating critical values for assessing the relevance of instruments used within an instrumental variables estimator. Rather than tackling all seven dimensions of the enforcement approach as separate regressors, we collapse these dimensions into a single index by summing the indicators of more cooperation (as opposed to less cooperation) across the enforcement approach dimensions. This index distinguishes enforcement strategies along a spectrum of cooperation. The lowest point of this index $(=0)$ reflects a weakly cooperative strategy, while the highest point on this index $(=7)$ reflects a strongly cooperative strategy.

We test the exogeneity of this cooperation index. To implement the exogeneity tests, we use three instruments that are expected to affect the enforcement approach but not independently affect facilities' audit 
decisions: (1) time since the state agency gained primacy to implement the NPDES program, (2) two-year lagged state inspections, and (3) two-year lagged federal inspections. ${ }^{14}$ Based on both partial $F$-test and minimum Eigenvalue statistics, these instruments appear relevant, that is, they help to explain the magnitude of the enforcement approach index. Based on both Sargan and Basman test of Overidentifying Restrictions statistics, the instruments do not appear invalid, i.e., they do not affect audit frequency. Most important, both $\mathrm{Wu}-$ Hausman and Durban test of Exogeneity statistics fail to reject the null hypothesis of exogeneity. All of these conclusions are fully robust to the time period analyzed and the regressor set used for estimation. ${ }^{15}$ Moreover, these conclusions are fully robust to the use of a single instrument time since gaining primacy, which represents the strongest instrument from a theoretical perspective. Specifically, after controlling for various government interventions and the overall enforcement approach, state primacy should not directly affect facilities' audit decisions, that is, the effect of state primacy should be only indirect. Given these conclusions, we do not employ an instrumental variables estimator since the benefits appear outweighed by the costs of reduced efficiency in the estimates, that is, performing instrumental variables estimation when the regressors are uncorrelated with the error process involves an important cost "the asymptotic variance of the IV estimator is always larger, and sometimes much larger" (Wooldridge, 2002, p. 490).

As another important econometric consideration, the measure of environmental management is audit frequency; thus, the dependent variable represents a non-negative sum of discrete events, that is, count data. Accordingly, this study employs a standard count data estimator, the Poisson model (Cameron and Trivedi, 1998), while invoking robust standard errors.

The collected data measure audit frequency over multiple years $(1999,2000,2001)$ for each sampled facility. To accommodate the panel structure of these data, the analysis employs two estimation approaches.

\footnotetext{
${ }^{14}$ Anton et al. (2004) use additionally lagged measures of inspections in order to test the exogeneity of environmental management when environmental performance is the dependent variable.

${ }^{15}$ Depending on the time period and regressor set, the partial $F$-test $p$-values lie between 0.0001 and 0.0069 , the overidentifying restrictions test $p$-values lie between 0.260 and 0.849 , and the exogeneity test $p$-values lie between 0.154 and 0.492 .
} 
The first approach uses a between-group estimator, which collapses the panel data into a single cross-section by calculating the sample means for the dependent variable and all the independent variables and then estimates the functional relationship based on the calculated mean values. The second approach considers each year of data as a separate crosssection and estimates the functional relationship for each year separately within a joint system of equations that constructs a separate equation for each year. Joint estimation of the three year-specific equations increases the efficiency of the estimates by exploiting the correlation across the three equations' error terms. Estimation of individual years proves useful because it allows the study to assess whether the effect of overall enforcement strategy is statistically significant in each year of the sample. ${ }^{16}$

The empirical analysis considers three regressor sets that differ based on the exclusion or inclusion of intervention-related factors. Model 1 excludes all of the intervention-related factors. Model 2 includes only the specific adjustment factors. Model 3 includes both the specific adjustment and the general threat factors. By excluding the interventionrelated factors, Model 1 allows the estimated effects of the overall enforcement strategy to absorb all of the influences associated with any differential use of inspections and enforcement actions. Moreover, the empirical analysis considers two model sets that differ based on the temporal structure of the data. Model Set A includes the regressors needed to implement the between-group estimator, while Model Set B includes the regressors needed to generate the year-specific estimates.

Table 2 reports the between-group estimates for Model Set A (Models A1, A2, and A3). Table 3 reports the year-specific estimates for Model Set B (Models B1, B2, and B3). Regarding the control factors, an assessment of the year-specific estimates (Model Set B) generates

\footnotetext{
${ }^{16}$ While the dependent variable - audit frequency - and most of the regressors vary over the sample period (1999-2001), the measures capturing the overall enforcement strategy do not vary over the sample period for a given facility. The survey questions generating these measures either explicitly or implicitly instruct the respondents to consider the preceding three-year period as a whole. Due to this lack of variation over time, use of the between-group estimator seems the most appropriate estimation approach since this approach considers the three-year period as a single cross-section. Then again, the analysis may reasonably assume that the measures of overall enforcement strategy sufficiently apply to each individual year as well as they apply to the whole three-year period.
} 
Table 2: Poisson between-group estimation of audit counts: Model set A.

\begin{tabular}{|c|c|c|c|c|c|c|}
\hline \multirow[b]{2}{*}{ Variable } & \multicolumn{2}{|c|}{ Model A1 } & \multicolumn{2}{|c|}{ Model A2 } & \multicolumn{2}{|c|}{ Model A3 } \\
\hline & Coeff. & $p$ & Coeff. & $p$ & Coeff. & $p$ \\
\hline \multicolumn{7}{|c|}{ Primary Explanatory Variables } \\
\hline $\begin{array}{l}\text { Generally cooperative (vs generally } \\
\text { coercive) }\end{array}$ & 1.4814 & 0.008 & 1.5282 & 0.004 & 1.4542 & 0.007 \\
\hline $\begin{array}{l}\text { Always fair treatment (vs sometimes } \\
\text { fair treatment) }\end{array}$ & -0.5253 & 0.093 & -0.5430 & 0.076 & -0.5571 & 0.070 \\
\hline $\begin{array}{l}\text { Same individual regulator (vs multiple } \\
\text { regulators) }\end{array}$ & 0.4304 & 0.092 & 0.4625 & 0.065 & 0.4416 & 0.079 \\
\hline $\begin{array}{l}\text { No request for assistance from } \\
\text { regulator's supervisor (vs request) }\end{array}$ & 0.8082 & 0.008 & 0.7496 & 0.009 & 0.7450 & 0.009 \\
\hline $\begin{array}{l}\text { No request for assistance from elected } \\
\text { official (vs request) }\end{array}$ & -0.0497 & 0.936 & 0.0627 & 0.912 & 0.0821 & 0.887 \\
\hline State is ty & 0.1649 & 0.764 & 0.0938 & 0.862 & 0.1179 & 0.837 \\
\hline Always likely to allow access (vs & 0.0004 & 0.999 & -0.0121 & 0.979 & -0.0265 & 0.955 \\
\hline
\end{tabular}
likely/somewhat likely)

\section{Control Factors}

Organic chemical manufacturing (vs "other")

Inorganic chemical manufacturing (vs "other")

Major facility classification (vs minor)

$$
\begin{array}{llllll}
-0.0681 & 0.886 & -0.0871 & 0.855 & -0.1488 & 0.696
\end{array}
$$$$
\begin{array}{llllll}
-0.7404 & 0.039 & -0.6626 & 0.056 & -0.7232 & 0.031
\end{array}
$$

Facility employees (count)

Age of facility (years)

Facility's experience with NPDES system (years)

Facility owned by publicly-held firm (vs privately-held)

Preceding calendar year state inspections (count)

Preceding calendar year federal inspections (count)

Preceding calendar year enforcement actions (count)

$$
\begin{array}{rrrrrr}
0.4963 & 0.104 & 0.5532 & 0.085 & 0.7551 & 0.089 \\
-0.0002 & 0.415 & -0.0003 & 0.242 & -0.0004 & 0.145 \\
0.0054 & 0.238 & 0.0048 & 0.284 & 0.0046 & 0.328 \\
-0.0260 & 0.098 & -0.0295 & 0.057 & -0.0262 & 0.085 \\
& & & & & \\
-0.4795 & 0.229 & -0.3402 & 0.412 & -0.3505 & 0.379
\end{array}
$$$$
\begin{array}{llll}
0.0202 & 0.714 & -0.0319 & 0.956
\end{array}
$$$$
\begin{array}{llll}
-3.5870 & 0.018 & -3.3501 & 0.037
\end{array}
$$$$
\begin{array}{llll}
0.1459 & 0.213 & 0.1389 & 0.189
\end{array}
$$

Annual state inspections of others/no. of other facilities

Annual federal inspections of others/no. of other facilities

Annual enforcement actions at others/no. of other facilities 
Table 2: (Continued)

\begin{tabular}{lcccccc}
\hline & \multicolumn{2}{c}{ Model A1 } & \multicolumn{2}{c}{ Model A2 } & \multicolumn{2}{c}{ Model A3 } \\
\cline { 2 - 7 } Variable & Coeff. & $p$ & Coeff. & $p$ & Coeff. & \multicolumn{1}{c}{$p$} \\
\hline LR test of zero slopes $\left[\chi^{2}\right]$ & 437.6 & 0.000 & 523.8 & 0.000 & 546.7 & 0.000 \\
Pseudo $R^{2}$ & & 0.1452 & & 0.1737 & & 0.1813 \\
Goodness of fit $\left[\chi^{2}\right]$ & 2034 & 0.000 & 1947 & 0.000 & 1924 & 0.000 \\
LR test: equal slopes for individual & 10.20 & 0.117 & 11.27 & 0.080 & 10.57 & 0.103 \\
$\quad$ relationship measures $\left[\chi^{2}\right]$ & & & & & & \\
Sample size & & 215 & & 215 & & 215 \\
\hline
\end{tabular}

Notes: Each model also includes an intercept term. $p$-values based on robust standard errors.

conclusions for each sample year that are identical to those supported by an assessment of the between-group estimates (Model Set A). Thus, for the sake of brevity, we report only the coefficients relating to the overall enforcement strategy measures for Model Set B in Table 3.

\section{Interpretation of Effects not related to Enforcement and Monitoring}

Before interpreting the effects of the overall enforcement strategy on audit frequency, along with the effects of intervention-related factors, this subsection interprets the effects not related to enforcement and monitoring. For this interpretation, we focus on the estimation results stemming from Model Set A. Results from Model Set B generate nearly identical conclusions.

These individual conclusions follow First, Inorganic chemical manufacturing facilities audit less frequently than "other" chemical manufacturing facilities. This result may indicate that production processes influence the costs or benefits of implementing audits. Specifically, organic chemical production processes are easier to audit and/or the information gleaned from audits is more beneficial for modifying organic chemical production processes. Second, Major facilities audit more frequently than minor facilities. Perhaps this result indicates the presence of economies of scale with respect to audit frequency. Third, More experienced facilities audit less frequently. Consistent with our a priori expectations, more experienced facilities appear to see a lesser need to glean insight from audits, that is, experience substitutes for audit findings. 
Table 3: Poisson joint estimation of year-specific equations for audits: Model set B.

\begin{tabular}{|c|c|c|c|c|c|c|}
\hline \multirow[b]{2}{*}{ Variable } & \multicolumn{2}{|c|}{ Model B1 } & \multicolumn{2}{|c|}{ Model B2 } & \multicolumn{2}{|c|}{ Model B3 } \\
\hline & Coeff. & $p$ & Coeff. & $p$ & Coeff. & $p$ \\
\hline \multicolumn{7}{|c|}{ Year $1999[N=215]$} \\
\hline $\begin{array}{l}\text { Generally cooperative (vs generally } \\
\text { coercive) }\end{array}$ & 1.3653 & 0.025 & 1.3927 & 0.017 & 1.4395 & 0.027 \\
\hline $\begin{array}{l}\text { Always fair treatment (vs sometimes } \\
\text { fair treatment) }\end{array}$ & -0.4578 & 0.143 & -0.4489 & 0.148 & -0.4434 & 0.155 \\
\hline $\begin{array}{l}\text { Same individual regulator (vs multiple } \\
\text { regulators) }\end{array}$ & 0.3116 & 0.215 & 0.2939 & 0.250 & 0.3052 & 0.246 \\
\hline $\begin{array}{l}\text { No request for assistance from } \\
\text { regulator's supervisor (vs request) }\end{array}$ & 0.6797 & 0.053 & 0.7243 & 0.044 & 0.7392 & 0.041 \\
\hline $\begin{array}{l}\text { No request for assistance from elected } \\
\text { official (vs request) }\end{array}$ & -0.1290 & 0.846 & -0.1824 & 0.781 & -0.1183 & 0.859 \\
\hline State is typical regulator (vs federal) & $\mathrm{N} / \mathrm{A}$ & $\mathrm{N} / \mathrm{A}$ & $\mathrm{N} / \mathrm{A}$ & $\mathrm{N} / \mathrm{A}$ & $\mathrm{N} / \mathrm{A}$ & $\mathrm{N} / \mathrm{A}$ \\
\hline $\begin{array}{l}\text { Always likely to allow access (vs } \\
\text { likely/somewhat likely) }\end{array}$ & -0.0580 & 0.904 & -0.0179 & 0.971 & -0.0375 & 0.939 \\
\hline $\begin{array}{l}\text { LR test: equal slopes for individual } \\
\text { relationship measures }\left[\chi^{2}\right]\end{array}$ & 11.96 & 0.063 & 12.65 & 0.049 & 11.63 & 0.071 \\
\hline
\end{tabular}
Year $2000[N=215]$

\begin{tabular}{lcccccc}
$\begin{array}{l}\text { Generally cooperative (vs generally } \\
\text { coercive) }\end{array}$ & 1.5273 & 0.003 & 1.5806 & 0.001 & 1.5602 & 0.003 \\
$\begin{array}{c}\text { Always fair treatment (vs sometimes } \\
\text { fair treatment) }\end{array}$ & -0.5571 & 0.096 & -0.5869 & 0.081 & -0.5949 & 0.079 \\
$\begin{array}{c}\text { Same individual regulator (vs multiple } \\
\text { regulators) }\end{array}$ & 0.4598 & 0.082 & 0.4610 & 0.079 & 0.4447 & 0.090 \\
$\begin{array}{c}\text { No request for assistance from } \\
\text { regulator's supervisor (vs request) }\end{array}$ & 0.8088 & 0.010 & 0.7912 & 0.009 & 0.8087 & 0.007 \\
$\begin{array}{c}\text { No request for assistance from elected } \\
\text { official (vs request) }\end{array}$ & 0.0171 & 0.979 & 0.0581 & 0.924 & 0.0362 & 0.951 \\
$\begin{array}{c}\text { State is typical regulator (vs federal) } \\
\text { Always likely to allow access (vs } \\
\text { likely/somewhat likely) }\end{array}$ & -0.0028 & 0.955 & 0.0151 & 0.973 & 0.0226 & 0.961 \\
$\begin{array}{c}\text { LR test: equal slopes for individual } \\
\text { relationship measures }\left[\chi^{2}\right]\end{array}$ & 20.62 & 0.002 & 21.30 & 0.002 & 21.38 & 0.002 \\
\hline
\end{tabular}


Table 3: (Continued)

\begin{tabular}{|c|c|c|c|c|c|c|}
\hline \multirow[b]{2}{*}{ Variable $^{a}$} & \multicolumn{2}{|c|}{ Model B1 } & \multicolumn{2}{|c|}{ Model B2 } & \multicolumn{2}{|c|}{ Model B3 } \\
\hline & Coeff. & $p$ & Coeff. & $p$ & Coeff. & $p$ \\
\hline \multicolumn{7}{|c|}{ Year 2001 $[N=215]$} \\
\hline $\begin{array}{l}\text { Generally cooperative (vs generally } \\
\text { coercive) }\end{array}$ & 1.4635 & 0.010 & 1.4850 & 0.008 & 1.2388 & 0.008 \\
\hline $\begin{array}{l}\text { Always fair treatment (vs sometimes } \\
\text { fair treatment) }\end{array}$ & -0.5616 & 0.083 & -0.5845 & 0.061 & -0.6646 & 0.029 \\
\hline $\begin{array}{l}\text { Same individual regulator (vs multiple } \\
\text { regulators) }\end{array}$ & 0.3799 & 0.176 & 0.4361 & 0.091 & 0.4280 & 0.090 \\
\hline $\begin{array}{l}\text { No request for assistance from } \\
\text { regulator's supervisor (vs request) }\end{array}$ & 0.8552 & 0.003 & 0.6289 & 0.019 & 0.5737 & 0.037 \\
\hline $\begin{array}{l}\text { No request for assistance from elected } \\
\text { official (vs request) }\end{array}$ & -0.0940 & 0.872 & 0.3730 & 0.573 & 0.3982 & 0.567 \\
\hline State is typical regulator (vs federal) & $\mathrm{N} / \mathrm{A}$ & $\mathrm{N} / \mathrm{A}$ & $\mathrm{N} / \mathrm{A}$ & $\mathrm{N} / \mathrm{A}$ & $\mathrm{N} / \mathrm{A}$ & $\mathrm{N} / \mathrm{A}$ \\
\hline $\begin{array}{l}\text { Always likely to allow access } \\
\text { (vs likely/somewhat likely) }\end{array}$ & 0.0564 & 0.901 & 0.0093 & 0.983 & -0.0550 & 0.903 \\
\hline $\begin{array}{l}\text { LR test: equal slopes for individual } \\
\text { relationship measures }\left[\chi^{2}\right]\end{array}$ & 10.01 & 0.124 & 9.64 & 0.141 & 10.39 & 0.104 \\
\hline LR test of zero slopes $\left[\chi^{2}\right]$ & 1179 & 0.000 & 1374 & 0.000 & 1497 & 0.000 \\
\hline Pseudo $R^{2}$ & & 0.1346 & & 0.1569 & & 0.1709 \\
\hline Goodness of & 6040 & 0.000 & 5845 & 0.000 & 5722 & 0.000 \\
\hline
\end{tabular}

Notes: Each model also includes an intercept term and all the regressors shown in Table 2 except the "State is Typical Regulator (versus Federal)" indicator, which lacks sufficient variation.

$p$-values based on robust standard errors.

These conclusions are fully robust to the inclusion of deterrence factors as regressors.

\section{Interpretation of Effects related to Enforcement and Monitoring}

This subsection interprets the effects of the overall enforcement strategy on audit frequency, along with the effects of intervention-related factors.

The between-group estimation results support the following conclusions, which are robust to the choice of regressor set, with a single minor exception, and robust to the time period analyzed, with a very few exceptions: First, Greater cooperation in general leads to more frequent audits. Second, Interaction with the same individual regulator 
leads to more frequent audits than does interaction with multiple regulators. Thus, similar to cooperation in general, stability of the regulatorregulated facility relationship increases audit frequency, consistent with the cooperative model. Third, The failure to request assistance from the regulator's supervisor leads to more frequent audits than does a request for assistance. Thus, a higher quality regulator-regulated facility relationship apparently increases audit frequency, similar to cooperation in general, again consistent with the cooperative model. Fourth, In contrast to the request for assistance from the regulator's supervisor, a request for assistance from an elected official does not influence audit frequency, providing support for neither the cooperative model nor the noncooperative model. As one interpretation of these two related results, the request for assistance from a regulator's supervisor undermines cooperation more so than a request to an elected official. Fifth, Audit frequency does not appear to depend on either the type of typical regulator - state versus federal - or a facility's willingness to allow a regulator access to its operations without prior notification. Thus, neither proximity to a regulator nor the level of trust supported by the regulator-regulated relationship influences audit frequency, providing support for neither theoretical model.

In stark contrast to all of these conclusions, "always fair" treatment leads to less frequent audits than does "sometimes fair" treatment, consistent with the noncooperative model. Put differently, by treating a facility sometimes unfairly, a regulator is apparently able to prompt more frequent auditing. In other words, occasional unfair treatment may increase auditing effort. This result may reveal that a regulator who always treats a facility fairly has been "captured," while a regulator who treats a facility in a more balanced fashion retains its leverage with a regulated facility. This conclusion supports the noncooperative model.

As the exceptions to these general conclusions, the year 1999-specific estimates do not support the conclusion relating to the fairness of treatment and the contrast between same regulator and multiple regulators. As a lesser point, the year 2001-specific results do not support the conclusion relating to the contrast between same regulator and multiple regulators within Model B1.

In sum, consideration of all the individual measures of the regulatorregulated facility relationship offers a rich understanding of the interplay between regulator and regulated facility. 
Lastly, we explore the role of government interventions - inspections and enforcement. Since conclusions are robust to the choice of regressor set (with a single minor exception), greater cooperation leads to more frequent auditing even when the analysis controls for the use of inspections and enforcement actions and the threat of their use.

To complement this understanding, we interpret the effects of intervention-related factors. Based on the between-group estimation results shown in Table 2, greater use of federal inspections apparently prompts less frequent audits. This results is consistent with the cooperative model and with the reported conclusion that greater cooperation prompts more frequent audits. Perhaps, federal inspections are less cooperative and this weaker cooperation undermines efforts to audit frequently. This conclusion is robust to the choice of regressor set. ${ }^{17}$

\section{Separate Analysis of Major Facilities and Minor Facilities}

We next assess the robustness of our conclusions by splitting the sample between major facilities $(N=88)$ and minor facilities $(N=127)$. We estimate the two sub-samples using both Poisson between-group estimation based on Model Set A and Poisson joint estimation of yearspecific equations based on Model Set B. Table 4ba and b reports the former estimates; the latter estimates are available upon request. Tables 4 ba and 4 bb display the results for major and minor facilities, respectively. By splitting the sample, we expect reductions in the levels of significance. Not surprisingly then, Tables 4 ba reveals that two of

\footnotetext{
${ }^{17}$ We assess the robustness of the estimation results and conclusions by employing three regressor sets and two estimation approaches. We also assess robustness by exploring whether the results are sensitive to the inclusion of EPA regional indicators as regressors. All of the individual conclusions relating to the regulator-regulated facility relationship are fully robust to the inclusion of the EPA regional indicators as regressors based on the preferable estimation approach of between-group estimation, regardless of the regressor set. Moreover, the year-specific results for Model Set B support the same conclusions for the years 2000 and 2001, regardless of the regressor set, even though the statistical significance of the coefficient associated with the request for supervisory assistance slips to the $12-15 \%$ level. In contrast, the 1999 year-specific results only marginally support the identified conclusions, with $p$-values ranging between 0.09 and 0.17 and generally acceptable significance $(p \leq 0.10)$ generated for only two dimensions: (1) contrast between the same regulator and multiple regulators and (2) request for supervisory assistance. Nevertheless, we conclude that our conclusions are strongly robust to the inclusion of EPA regional indicators.
} 
Table 4a: Poisson between-group estimation of audit counts: Model set A - split sample between major facilities.

\begin{tabular}{|c|c|c|c|c|c|c|}
\hline \multirow[b]{2}{*}{ Variable } & \multicolumn{2}{|c|}{ Model A1 } & \multicolumn{2}{|c|}{ Model A2 } & \multicolumn{2}{|c|}{ Model A3 } \\
\hline & Coeff. & $p$ & Coeff. & $p$ & Coeff. & $p$ \\
\hline \multicolumn{7}{|c|}{ Primary explanatory variables } \\
\hline $\begin{array}{l}\text { Generally cooperative (vs generally } \\
\text { coercive) }\end{array}$ & 2.1120 & 0.007 & 2.0752 & 0.003 & 2.1571 & 0.001 \\
\hline $\begin{array}{l}\text { Always fair treatment (vs sometimes } \\
\text { fair treatment) }\end{array}$ & -0.1834 & 0.663 & -0.1515 & 0.721 & -0.2618 & 0.544 \\
\hline $\begin{array}{l}\text { Same individual regulator (vs multiple } \\
\text { regulators) }\end{array}$ & 0.0297 & 0.930 & -0.0196 & 0.951 & -0.0910 & 0.771 \\
\hline $\begin{array}{l}\text { No request for assistance from } \\
\text { regulator's supervisor (vs request) }\end{array}$ & 1.0884 & 0.008 & 1.0856 & 0.008 & 1.0970 & 0.009 \\
\hline $\begin{array}{l}\text { No request for assistance from elected } \\
\text { official (vs request) }\end{array}$ & -0.2311 & 0.678 & -0.3689 & 0.499 & -0.4035 & 0.443 \\
\hline $\begin{array}{l}\text { tate is typical regulator ( } \mathrm{vs} f \\
\text { lways likely to allow access }\end{array}$ & 0.9443 & 0.237 & 1.0232 & 0.116 & 0.9211 & 0.162 \\
\hline
\end{tabular}

Always likely to allow access (vs likely/somewhat likely)

Organic chemical manufacturing (vs "other")

Inorganic chemical manufacturing (vs "other")

Facility employees (count)

Age of facility (years)

Facility's experience with NPDES system (years)

$\begin{array}{lllllll}\text { Facility owned by publicly held firm } & -0.7769 & 0.114 & -0.5775 & 0.301 & -0.5644 & 0.296\end{array}$ (vs privately held)

Preceding calendar year state inspections (count)

Preceding calendar year federal inspections (count)

$\begin{array}{lllll}\text { Preceding calendar year enforcement } & 0.0456 & 0.769 & 0.0908 & 0.541\end{array}$ actions (count)

Annual state inspections of others/No. of other facilities

Annual federal inspections of others/No. of other facilities

annual enforcement actions at others/No. of other facilities

\begin{tabular}{lcccc}
\hline Pseudo $R^{2}$ & 0.3104 & 0.3648 & 0.3747 & \\
Goodness of fit $\left[\chi^{2}\right]$ & 1181.15 & 0.0001114 .05 & 0.0001091 .95 & 0.000 \\
Sample size & 88 & 88 & 88 & \\
\hline
\end{tabular}


Table 4b: Poisson between-group estimation of audit counts: Model set A - split sample between minor facilities.

\begin{tabular}{|c|c|c|c|c|c|c|}
\hline \multirow[b]{2}{*}{ Variable } & \multicolumn{2}{|c|}{ Model B1 } & \multicolumn{2}{|c|}{ Model B2 } & \multicolumn{2}{|c|}{ Model B3 } \\
\hline & Coeff. & $p$ & Coeff. & $p$ & Coeff. & $p$ \\
\hline \multicolumn{7}{|c|}{ Primary explanatory variables } \\
\hline $\begin{array}{l}\text { Generally cooperative (vs generally } \\
\text { coercive) }\end{array}$ & 0.8687 & 0.165 & 0.8991 & 0.107 & 0.9734 & 0.198 \\
\hline $\begin{array}{l}\text { Always fair treatment (vs } \\
\text { sometimes fair treatment) }\end{array}$ & -0.5416 & 0.164 & -0.5649 & 0.135 & -0.5286 & 0.139 \\
\hline $\begin{array}{l}\text { Same individual regulator (vs } \\
\text { multiple regulators) }\end{array}$ & 0.6420 & 0.056 & 0.6859 & 0.041 & 0.9074 & 0.013 \\
\hline $\begin{array}{l}\text { No request for assistance from } \\
\text { regulator's supervisor (vs } \\
\text { request) }\end{array}$ & 0.6084 & 0.111 & 0.5914 & 0.081 & 0.6022 & 0.111 \\
\hline $\begin{array}{l}\text { No request for assistance from } \\
\text { elected official (vs request) }\end{array}$ & 1.4323 & 0.027 & 1.4468 & 0.045 & 1.4930 & 0.012 \\
\hline $\begin{array}{l}\text { State is typical regulator (vs } \\
\text { federal) }\end{array}$ & 0.4254 & 0.499 & 0.3166 & 0.579 & 0.1759 & 0.758 \\
\hline Always likely to allow access (vs & -0.3428 & 0.506 & -0.4267 & 0.388 & -0.2045 & 0.679 \\
\hline \multicolumn{7}{|c|}{ Control Factors } \\
\hline $\begin{array}{l}\text { Organic chemical manufacturing } \\
\text { (vs "other") }\end{array}$ & 0.1723 & 0.661 & 0.2595 & 0.536 & 0.3037 & 0.432 \\
\hline $\begin{array}{l}\text { Inorganic chemical manufacturing } \\
\text { (vs "other") }\end{array}$ & -0.3194 & 0.442 & -0.1385 & 0.758 & -0.1557 & 0.730 \\
\hline Facility employees (count) & 0.0001 & 0.941 & 0.0008 & 0.131 & 0.0008 & 0.141 \\
\hline Age of facility (years) & 0.0043 & 0.497 & 0.0038 & 0.539 & 0.0057 & 0.363 \\
\hline $\begin{array}{l}\text { Facility's experience with NPDES } \\
\text { system (years) }\end{array}$ & -0.0081 & 0.612 & -0.0080 & 0.632 & -0.0103 & 0.541 \\
\hline $\begin{array}{l}\text { Facility owned by publicly held } \\
\text { firm (vs privately held) }\end{array}$ & -0.2785 & 0.423 & -0.3781 & 0.300 & -0.3525 & 0.322 \\
\hline $\begin{array}{l}\text { Preceding calendar year state } \\
\text { inspections (count) }\end{array}$ & & & -0.2036 & 0.170 & -0.3469 & 0.067 \\
\hline $\begin{array}{l}\text { Preceding calendar year federal } \\
\text { inspections (count) }\end{array}$ & & & -6.1139 & 0.001 & -5.3528 & 0.028 \\
\hline $\begin{array}{l}\text { Preceding calendar year } \\
\text { enforcement actions (count) }\end{array}$ & & & -6.8430 & 0.052 & -7.2186 & 0.051 \\
\hline $\begin{array}{l}\text { Annual state inspections of } \\
\text { others/No. of other facilities }\end{array}$ & & & & & 0.4370 & 0.138 \\
\hline $\begin{array}{l}\text { Annual federal inspections of } \\
\text { others/No. of other facilities }\end{array}$ & & & & & -34.0741 & 0.079 \\
\hline $\begin{array}{l}\text { Annual enforcement actions at } \\
\text { others/No. of other facilities }\end{array}$ & & & & & 9.9151 & 0.404 \\
\hline Pseudo $R^{2}$ & 0.1067 & & 0.1273 & & 0.1623 & \\
\hline Goodness of fit $\left[\chi^{2}\right]$ & 1512.33 & 0.000 & 1465.26 & 0.000 & 1315.62 & 0.000 \\
\hline Sample size & 127 & & 127 & & 127 & \\
\hline
\end{tabular}

Notes: Each model also includes an intercept term. $p$-values based on robust standard errors. 
the four effects of the regulator-regulated relationship found significant based on estimation of the full sample lose their statistical significance $(p>0.10)$ based on the smaller subsample of major facilities. The effects of "generally cooperative" and "no request for assistance from the regulator's supervisor" remain statistically significant. Despite any loss of significance, the four relevant coefficient signs remain the same as when based on the full sample.

Similarly, Table $4 \mathrm{bb}$ reveals that one or two (depending on the model) of the four regulator-regulated relationship effects found significant based on the full sample lose their statistical significance based on the smaller sub-sample of minor facilities. The effects of "same individual regulator" and "no request for assistance from the regulator's supervisor" remain statistically significant in all three models. The effect of "generally cooperative" retains its statistical significance in Model A2. (The effect of "always fair treatment" is almost marginally significant given a $p$-value of 0.13 in Models A2 and A3.) Again, the four relevant coefficient signs remain the same. Interestingly, the effect of "no request for assistance from an elected official" becomes significantly positive. Clearly this effect differs between minor and major facilities. (The relevant test statistic is significant given $p$-values ranging between 0.02 and 0.05.)

Excepting the effect of requesting assistance from an elected official, we find that, in general, our conclusions are moderately robust with respect to the type of facility. Nevertheless, we admit that our analysis of major facilities does not generate results that support the same conclusions supported by the results generated from analysis of the full sample.

\section{Interactions between Overall Enforcement Approach and Government Interventions}

As our final assessment of robustness, we generate interactions between each of the seven overall enforcement approach dimensions and each of government intervention measures and then include these interactions as additional regressors in our estimation. Given our study's objective, we again focus on government interventions taken against specific facilities. Moreover, our estimation results reveal that government interventions taken against other similar facilities do not prove statistically significant. 
(Joint tests of significance for the three general threat factors based on Model A3 and Model B3 estimates generate statistics of 7.04 and 7.10, respectively, with p-values of 0.633 and 0.778 , respectively.) Thus, we focus on Models A2 and B2.

This assessment of robustness relies on interpreting 21 interactions in the between-group estimation and 63 interactions in the year-specific estimation. Given the large number of interactions, we interpret the results cautiously and pay more attention to the between-group estimates.

Rather than tabulating the many relevant individual coefficient estimates (31 between-group coefficient and 93 year-specific coefficients), we organize our results into meaningful categories. Table 5a displays the relevant calculations. First, we assess whether the three interactions associated with each overall enforcement dimension prove jointly significant. If not, we should focus on the initial sets of results displayed in Tables 2 and 3. As shown in Table 5a, based on the between-group estimates, the set of interactions prove significant for five of the seven dimensions. The interactions relating to trust (likelihood to allow the regulator access to facility operations without any prior announcement) are not jointly significant. And the data do not provide enough variation to assess the interactions relating to the distinction between state and federal

Table 5a: Marginal effects from poisson between-group estimation of audit counts involving interactions between regulator-regulated dimensions and government interventions as an extension of Model A2: Joint test of statistical significance for interactions by regulator-regulated dimension.

\begin{tabular}{lcc}
\hline Regulator-regulated dimension & Statistic & $p$-value \\
\hline Generally cooperative (vs generally coercive) & 4.23 & 0.040 \\
Always fair treatment (vs sometimes fair treatment) & 6.20 & 0.102 \\
Same individual regulator (vs multiple regulators) & 11.45 & 0.009 \\
No request for assistance from regulator's supervisor (vs request) & 19.21 & 0.000 \\
No request for assistance from elected official (vs request) & 10.58 & 0.014 \\
State is typical regulator (vs federal) & $\mathrm{n} / \mathrm{a}$ & $\mathrm{n} / \mathrm{a}$ \\
Always likely to allow access (vs likely/somewhat likely) & 2.65 & 0.266 \\
\hline
\end{tabular}

Note: ${ }^{a}$ This factor's interactions involving specific deterrence measures lack sufficient variation. 
regulators. The year-specific results support these same conclusions except in 5 of the 21 cases: general approach (Year 2000), same regulator versus multiple regulators (Year 2000), request for supervisory assistance (Year 1999), request for elected official's assistance (Year 2000), and announced regulatory access to facility operations (Year 1999).

Second, we assess the marginal effects associated with each individual overall enforcement approach dimension. We consider both the sign of the marginal effect and its statistical significance. Given the presence of statistically significant interactions, each marginal effect represents the sum of the main coefficient for each dimension and the three interaction coefficients, each multiplied by some particular value of the relevant government intervention factor. ${ }^{18}$

Tables $5 \mathrm{~b}$ and $5 \mathrm{c}$ tabulate the marginal effects calculated under certain monitoring and enforcement conditions, that is, specified values for state inspections, federal inspections, and enforcement actions. By construction, the main coefficients reflect marginal effects when all of the government intervention measures are set to zero, which represent the sample minima for these factors. The left panel of Table 5b displays these marginal effects. As a contrast, we calculate a second set of marginal effects by setting the government intervention factors to their sample maxima - 3 state inspections, 1 federal inspection, and 10.3 enforcement actions - for the between-group estimation. The right panel of Table 5b displays the resulting marginal effects. Lastly, we select the specific values for the government intervention factors carefully in order to generate for each individual overall enforcement approach dimension: (1) the most positive marginal effect, which represents the "best case for greater cooperation," and (2) the most negative marginal effect, which represents the "best case for weaker cooperation." Table $5 \mathrm{c}$ displays the most positive and most negative marginal effects in the left and right panels, respectively.

\footnotetext{
${ }^{18}$ For example, the marginal effect for the general relationship of cooperation versus coercion, denoted as $M$, equals the main coefficient for the general relationship, denoted as $G$, plus the interaction coefficient involving state inspections, denoted as IS, multiplied by the count of state inspections, denoted as CS, plus the interaction coefficient involving federal inspections, denoted as IF, multiplied by the count of federal inspections, denoted as CF, plus the interaction coefficient involving enforcement actions, denoted as $E$, multiplied by the count of enforcement actions, denoted as $\mathrm{CE}: \mathrm{M}=\mathrm{G}+(\mathrm{IS} \times \mathrm{CS})+(\mathrm{IF} \times \mathrm{CF})+(\mathrm{E} \times \mathrm{CE})$.
} 
Table 5b: Marginal effects from poisson between-group estimation of audit counts involving interactions between regulator-regulated dimensions and government interventions as an extension of Model A2: Marginal effects - each government intervention measure set to sample minimum or maximum.

\begin{tabular}{lcccc}
\hline & \multicolumn{2}{c}{ Sample minima } & \multicolumn{2}{c}{ Sample maxima } \\
\cline { 2 - 5 } Regulator-regulated dimension & Magnitude & $p$-value & Magnitude & $p$-value \\
\hline $\begin{array}{l}\text { Generally cooperative (vs generally } \\
\quad \text { coercive) }\end{array}$ & 2.3818 & 0.009 & -21.3002 & 0.048 \\
$\begin{array}{l}\text { Always fair treatment (vs sometimes fair } \\
\quad \text { treatment) }\end{array}$ & -0.8582 & 0.041 & 42.2764 & 0.014 \\
$\begin{array}{l}\text { Same individual regulator (vs multiple } \\
\quad \text { regulators) }\end{array}$ & 0.7041 & 0.027 & -39.1516 & 0.007 \\
$\begin{array}{l}\text { No request for assistance from regulator's } \\
\quad \text { supervisor (vs request) }\end{array}$ & 0.7093 & 0.017 & -37.7211 & 0.021 \\
$\begin{array}{l}\text { No request for assistance from elected } \\
\quad \text { official (vs request) }\end{array}$ & 1.8934 & 0.001 & -50.9523 & 0.002 \\
$\begin{array}{l}\text { State is typical regulator (vs federal) } \\
\begin{array}{l}\text { Always likely to allow access (vs } \\
\quad \text { likely/somewhat likely) }\end{array}\end{array}$ & $\mathrm{n} / \mathrm{a}$ & $\mathrm{n} / \mathrm{a}$ & $\mathrm{n} / \mathrm{a}$ & $\mathrm{n} / \mathrm{a}$ \\
\hline
\end{tabular}

Note: ${ }^{a}$ This factor's interactions involving specific deterrence measures lack sufficient variation.

An assessment of the first two sets of marginal effects reveals the following conclusions. As with the initial set of estimation results, when regulatory monitoring and enforcement is sufficiently low, most of the individual overall enforcement approach dimensions demonstrate that greater cooperation leads to more frequent audits yet "always fair treatment" leads to less frequent audits than does "sometimes unfair treatment." In contrast to the initial results, the absence of a request for an elected official's assistance leads to more frequent audits than does the presence of such a request. However, when regulatory monitoring and enforcement are sufficiently high, each conclusion flips. The significantly positive effects become significantly negative, while the one significantly negative effect becomes significantly positive. Thus, the marginal effects for five of the seven dimensions range between negative and positive depending on regulatory conditions.

An assessment of the best cases for greater cooperation and weaker cooperation support the same conclusions, as shown in Table 5c. Each of the same marginal effects ranges between negative and positive. 
Table 5c: Marginal effects from poisson between-group estimation of audit counts involving interactions between regulator-regulated dimensions and government interventions as an extension of Model A2: Marginal effects - interventions set to support "best case" for greater/weaker cooperation.

\begin{tabular}{lcccc}
\hline $\begin{array}{l}\text { Regulator-regulated } \\
\text { dimension }\end{array}$ & \multicolumn{3}{c}{ Best Case for Cooperation } & \multicolumn{2}{c}{ Best Case for Coercion } \\
\cline { 2 - 5 } & Magnitude & $p$-value & Magnitude & $p$-value \\
\hline $\begin{array}{l}\text { Generally cooperative (vs generally } \\
\quad \text { coercive) }\end{array}$ & 2.3818 & 0.009 & -21.3002 & 0.048 \\
$\begin{array}{l}\text { Always fair treatment (vs sometimes } \\
\quad \text { fair treatment) }\end{array}$ & 43.5070 & 0.016 & -2.0888 & 0.510 \\
$\begin{array}{l}\text { Same individual regulator (vs } \\
\quad \text { multiple regulators) }\end{array}$ & 5.4870 & 0.007 & -43.9345 & 0.003 \\
$\begin{array}{l}\text { No request for assistance from } \\
\text { regulator's supervisor (vs request) }\end{array}$ & 0.7093 & 0.017 & -37.7211 & 0.021 \\
$\begin{array}{l}\text { No request for assistance from } \\
\quad \text { elected official (vs request) }\end{array}$ & 2.2254 & 0.006 & -51.2842 & 0.002 \\
$\begin{array}{l}\text { State is typical regulator (vs } \\
\quad \text { federal) }\end{array}$ & $\mathrm{n} / \mathrm{a}$ & $\mathrm{n} / \mathrm{a}$ & $\mathrm{n} / \mathrm{a}$ & $\mathrm{n} / \mathrm{a}$ \\
$\begin{array}{l}\text { Always likely to allow access (vs } \\
\quad \text { likely/ somewhat likely) }\end{array}$ & 8.7810 & 0.178 & -0.2616 & 0.670 \\
\hline
\end{tabular}

Note: ${ }^{a}$ This factor's interactions involving specific deterrence measures lack sufficient variation.

An assessment of the year-specific estimation results support identical conclusions in general. At one extreme, marginal effects prove significantly positive except as noted: same regulator versus multiple regulators (Year 2000) and unannounced access to facility operations (Year 1999), representing only 2 of 21 cases. At the other extreme, marginal effects prove significantly negative except as noted: generally cooperative versus generally coercive (Years 1999 and 2000), fair treatment (Years 1999 and 2001), same regulator versus multiple regulators (Years 2000 and 2001), and absence/presence of a request for an elected official's assistance (Years 2000 and 2001), representing only 7 of 21 cases.

In closing, we cautiously interpret the marginal effects generated by consideration of interactions between overall enforcement approach and government interventions because the dimensionality of 21 interactions in the between-group estimation and 63 interactions in the year-specific estimation is sizable. As important, marginal effects derived from sample 
maxima for government interventions obviously rely on extremes. While the presence of significant interactions clearly reveals that marginal effects depend on regulatory conditions, the presence of significantly negative marginal effects in the case of most dimensions and a significantly positive marginal effect for the fairness of regulatory treatment may not represent accurately the analytical results.

\section{Policy and Research Implications}

The conclusions generated by the empirical results possess clear policy and research implications First, Conclusions supported by the primary estimates imply that environmental regulators seeking to induce more frequent auditing should in general employ a more cooperative approach. However, these conclusions also imply that environmental regulators should not be overly fair; otherwise the regulators may lose their leverage with regulated facilities. Yet an assessment of interactions involving government intervention factors reveals that marginal effects appear to depend on regulatory monitoring and enforcement conditions. Based on extreme conditions, the marginal effects may differ in sign. Thus, the final policy implications may depend on regulatory monitoring and enforcement conditions. Second, These conclusions imply that future research on effects of the overall enforcement strategy employed by an environmental regulator should not view this strategy as unidimensional. Instead, future research should view the enforcement strategy as representing a relationship between a regulator and a regulated facility and attempt to measure multiple dimensions of this relationship because altering individual aspects of this relationship may have greater or lesser impacts on the behavior of regulated facilities.

\section{Appendix: Incomplete Response to Survey of Chemical Manufacturing Facilities}

This appendix assesses the incomplete response to our original survey of chemical manufacturing facilities. Given the survey's non-response rate of $73 \%$, the potential for sample selection bias is a valid concern. As the initial assessment of this concern, we compare the original 
sample of 1003 potentially eligible facilities to the 267 facilities that actually completed the survey. Based on this comparison, we find no systematic state or regional bias in survey participation. For example, only the Midwest region is slightly over-represented in the response group, and only the Northeast region is slightly under-represented. These differences, however, are small. In addition, across most of the states, the difference between representation in the original sample and representation in the response group averages less than $2 \%$. In contrast, our initial assessment reveals some difference in the participation of major facilities versus minor facilities. In the original sample, $69 \%$ of facilities are minor facilities and $31 \%$ are major facilities. In the group of survey respondents, major facilities are slightly over-represented at $39 \%$. This difference proves statistically significant.

As a stronger assessment, we test for sample selection bias using the first stage of the Heckman two-stage sample selection procedure (Heckman, 1979). Specifically, we assess whether any relevant factors appear to affect a facility's decision to complete our survey once it is contacted. This assessment reveals a bias in a single dimension: major facilities were more likely to respond to the survey than were minor facilities. Put differently, the Heckman analysis indicates that only the distinction between minor and major facilities proves important for explaining whether or not a contacted facility completed the administered survey. The Heckman analysis demonstrates that neither the preceding history of inspections nor the preceding enforcement actions against a particular facility explains whether or not a contacted facility responded to the survey. Moreover, the analysis demonstrates that the decision to respond is not explained by the EPA region in which a particular facility resides. Thus, even if the threat of inspections and enforcement actions varies across EPA regions, this variation does not explain whether or not a contacted facility responds to the survey. (The analysis is not able to control for variation across states in a similar fashion given the large number of individual states, relative to the sample size.)

From the first stage of the Heckman procedure, we do not generate an inverse Mills ratio and then incorporate the inverse Mills ratio as an explanatory factor in the estimation of audit frequency. Implementation of the Heckman two-step sample selection procedure permits only the use of ordinary least squares (OLS) in the second stage. Of course, use of 
OLS to estimate count data generates inconsistent, biased, and inefficient estimates (Cameron and Trivedi, 1998). Therefore, we implement only the first stage of the Heckman procedure.

As one last form of sample selection assessment, we incorporate information on discharges and effluent limits, for which data are publicly available only for major facilities, for both survey respondents and nonrespondents. Consistent with our final sample of analysis, our last form of assessment focuses exclusively on major facilities. Using two-sample means $T$-tests, we demonstrate that the sample of survey respondents and the sample of survey nonrespondent facilities generated extremely similar discharge-to-limit ratios (i.e., actual discharges divided by permitted limits) for the time period covered by the survey instrument: January 1999-March 2003. This analysis considers separately the two most prominent wastewater pollutants: total suspended solids (TSS) and biological oxygen demand (BOD). For the TSS discharge-to-limit ratio, both of the sample means equal 0.267 and the $t$-test, $p$-value is 0.969. For the BOD discharge-to-limit ratio, the two sample means are nearly identical -0.261 and 0.256 - and the $t$-test, $p$-value is 0.616 .

For all these reasons, the study does not correct for any potential sample selection bias. This lack of correction is consistent with recent prominently published studies of environmental management practices (Anton et al., 2004; Arimura et al., 2008).

\section{References}

American Society for Testing and Materials [ASTM] (2003), "Standard Practice for Environmental Regulatory Compliance Audits", 1-4.

Andreen, W. (2007), "Motivating Enforcement: Institutional Culture and the Clean Water Act", Pace Environmental Law Review, 24, $67-98$.

Anton, W. R., G. Deltas, and M. Khanna (2004), "Incentives for Environmental Self-Regulation and Implications for Environmental Performance", Journal of Environmental Economics and Management, 48, 632-54. 
Arimura, T., N. Darnall, and H. Katayama (2011), "Is ISO 14001 a Gateway to More Advanced Voluntary Action? The Case of Green Supply Chain Management", Journal of Environmental Economics and Management, 61, 170-82.

Arimura, T., A. Hibiki, and H. Katayama (2008), "Is a Voluntary Approach an Effective Environmental Policy Instrument? A Case for Environmental Management Systems", Journal of Environmental Economics and Management, 55(3), 281-95.

Ayers, I. and J. Braithwaite (1992), Responsive Regulation: Transcending the Deregulation Debate, New York: Oxford University Press.

Barla, P. (2007), "ISO 14001 Certification and Environmental Performance in Quebec's Pulp and Paper Industry", Journal of Environmental Economics and Management, 55, 291-306.

Becker, G. (1968), "Crime and Punishment: An Economic Approach", Journal of Political Economy, 76, 169-217.

Burby, R. (1995), "Coercive v. Cooperative Pollution Control: Comparative Study of State Programs to Reduce Erosion and Sedimentation Pollution in Urban Areas", Environmental Management, 19, 359-61. Burby, R. and R. Paterson (1993), "Improving Compliance with State Environmental Regulations", Journal of Policy Analysis and Management, 12, 753-6.

Cameron, A. C. and P. K. Trivedi (1998), Regression Analysis of Count Data, Cambridge, UK: Cambridge University Press.

Cohen, M. (2000), "Empirical Research on the Deterrent Effect of Environmental Monitoring and Enforcement", Environmental Law Reporter, 30, 10245-52.

Crow, M. (2000), "Beyond Experiments", Environmental Forum, 37(3), $18-29$.

Earnhart, D. (2004a), "Panel Data Analysis of Regulatory Factors Shaping Environmental Performance", Review of Economics and Statistics, 86(1), 391-401.

Earnhart, D. (2004b), "Regulatory Factors Shaping Environmental Performance at Publicly-Owned Treatment Plants", Journal of Environmental Economics and Management, 48(1), 655-81.

Earnhart, D. (2009), "The Influence of Facility Characteristics and Permit Conditions on the Effects of Environmental Regulatory Deterrence", Journal of Regulatory Economics, 36(3), 247-73. 
Ebihara, T. and D. Irminger (2005), "Correlation of Environmental Management Practices to Environmental Performance for the U.S. Chemical Manufacturing Industry", University of Kansas, School of Engineering, Working Paper.

EPA (1997), "EPA Strategic Plan", EPA/190-R-97-002.

EPA (1999), "EPA/CMA Root Cause Analysis Pilot Project", May 1999, Document No. EPA-305-R-99-001.

EPA (2000), "U.S. EPA Strategic Plan 2000", Washington, DC: Environmental Protection Agency.

Evans, M., L. Liu, and S. Stafford (2011), "Do Environmental Audits Improve Long-Term Compliance? Evidence from Manufacturing Facilities in Michigan", Journal of Regulatory Economics, 40, 279302.

Faure, M. (2012), "Effectiveness of Environmental Law: What Does the Evidence Tell Us?", William and Mary Environmental Law and Policy Review, 36, 293-300.

Glicksman, R. and D. Earnhart (2007), "The Comparative Effectiveness of Government Interventions on Environmental Performance in the Chemical Industry", Stanford Environmental Law Journal, 26, 112 39.

Harrison, K. (1995), "Is Cooperation the Answer? Canadian Environmental Enforcement in Comparative Context", Journal of Policy Analysis and Management, 14, 221-3.

Hawkins, K. (1984), Environment and Enforcement: Regulation and the Social Definition of Pollution, New York: Oxford University Press.

Heckman, J. (1979), "Sample Selection Bias as Specification Error", Econometrica, 47, 153-61.

Helland, E. (1998), "The Enforcement of Pollution Control Laws: Inspections, Violations, and Self-Reporting", Review of Economics and Statistics, 80(1), 141-53.

Kagan, R., N. Gunningham, and D. Thornton (2005), "Explaining Corporate Environmental Performance: How Does Regulation Matter?", Law and Society Review, 37, 51-61.

Karpoff, J., J. R. L. Jr., and E. W. Wehrly (2005), "The Reputational Penalties for Environmental Violations: Empirical Evidence", Journal of Law and Economics, 48, 653-75. 
Khanna, M. and W. R. Q. Anton (2002), "Corporate Environmental Management: Regulatory and Market-Based Incentives", Land Economics, 78(4), 539-58.

Khanna, M. and D. Widyawati (2011), "Fostering Regulatory Compliance: The Role of Environmental Self-Auditing and Audit Policies", Review of Law and Economics, 7, 129-63.

Magat, W. A. and W. K. Viscusi (1990), "Effectiveness of the EPA's Regulatory Enforcement: The Case of Industrial Effluent Standards", Journal of Law and Economics, 33, 331-60.

Malloy, T. (2003), "Regulation, Compliance and the Firm", Temple Law Review, 76, 451-4.

Markel, D. (2000), "The Role of Deterrence-Based Enforcement in a 'Reinvented' State/Federal Relationship: The Divide Between Theory and Reality", Harvard Envtl Law Review, 24, 1-5.

Markel, D. (2005), "Slack' in the Administrative State and its Implications for Governance: The Issue of Accountability", Oregon Law Review, 84, 1-22.

Mintz, J. (1995), Enforcement at the EPA: High Stakes and Hard Choices, Austin: University of Texas Press.

Nakamura, M., T. Takahashi, and I. Vertinsky (2001), "Why Japanese Firms Choose to Certify: A Study of Managerial Responses to Environmental Issues", Journal of Environmental Economics and Management, 42, 23-52.

Paxson, M. C. (1992), "Response Rates for 183 Studies", Working Paper Washington State University, Washington State University.

Rechtschaffen, C. (1998), "Deterrence vs. Cooperation and the Evolving Theory of Environmental Enforcement", Southern California Law Review, 71, 1181-8.

Rechtschaffen, C. (2004), "Promoting Pragmatic Risk Regulation: Is Enforcement Discretion the Answer?", University of Kansas Law Review, 52, 1327-61.

Rechtschaffen, C. and D. Markell (2003), Reinventing Environmental Enforcement and the State/Federal Relationship, Washington, DC: Environmental Law Institute.

Sah, R. (1991), "Social Osmosis and Patterns of Crime", Journal of Political Economy, 99(6), 1272-95.

Scholz, J. (1984), "Cooperation, Deterrence, and the Ecology of Regulatory Enforcement", Law and Society Review, 18, 179-80. 
Short, J. and M. Toffel (2010), "Making Self-Regulation More Than Merely Symbolic: The Critical Role of the Legal Environment", Administrative Science Quarterly, 55, 361-96.

Spence, D. (2001), "Can the Second Generation Learn from the First?

Understanding the Politics of Regulatory Reform", Capitol University Law Review, 29, 205-7.

Stahl, M. M. (1995), "Enforcement in Transition", The Environmental Forum, 12, 19-25.

Stock, J. and M. Yogo (2005), "Testing for Weak Instruments in Linear IV Regression", in Identification and Inference for Econometric Models: Essays in Honor of Thomas Rothenberg, ed. D. W. K. Andrews and J. H. Stock, New York: Cambridge University Press, 80-108.

Stoughton, M., J. Herb, J. Sullivan, and M. Crow (2001), "Toward Integrated Approaches to Compliance Assurance", Environmental Law Report, 31, 11266-83.

Stretesky, P. and J. Gabriel (2005), "Self-Policing and the Environment: Predicting Self-Disclosure of Clean Air Act Violations under the U.S. Environmental Protection Agency's Audit Policy", Society and Natural Resources, 18(10), 871-87.

Toffel, M. and J. Short (2011), "Coming Clean and Cleaning Up: Does Voluntary Self-Reporting Indicate Effective Self-Policing", Journal of Law and Economics, 54, 609-49.

Vandenbergh, M. (2003), "Beyond Elegance: A Testable Typology of Social Norms in Corporate Environmental Compliance", Stanford Environmental Law Journal, 22, 63-4.

Wilson, C. L. and W. L. Thomas (1998), "Environmental Audits and Corporate Strategies", Corporate Environmental Strategy, 5, 4-17. 